\title{
Coil Embolization for a Ruptured Posterior Cerebral Artery Aneurysm With Vertebrobasilar Dolichoectasia -Case Report-
}

\author{
Shinya YAMAgUCHI, ${ }^{1}$ Osamu ITO, ${ }^{2}$ Yoshihisa MAEDA, ${ }^{3}$ \\ Hideki MURATA, ${ }^{3}$ Naoyuki IMAMOTO, ${ }^{3}$ Fumiaki YUHI, ${ }^{3}$ \\ Yoshihiro NATORI, ${ }^{3}$ and Koichiro MATSUKADO ${ }^{1}$
${ }^{1}$ Department of Neurosurgery, Hamanomachi Hospital, Fukuoka, Fukuoka; ${ }^{2}$ Department of Neurosurgery, Shin-Koga Hospital, Kurume, Fukuoka;
${ }^{3}$ Department of Neurosurgery, Iizuka Hospital, Iizuka, Fukuoka

\begin{abstract}
A 74-year-old man suffered sudden loss of consciousness at home. Computed tomography revealed severe subarachnoid hemorrhage and an unusual posterior cerebral artery (PCA) aneurysm with vertebrobasilar dolichoectasia (VBD). The aneurysm was located in the right hypothalamus. VBD associated with a distal lesion makes endovascular treatment difficult because of the elongation and tortuosity of the access route. However, endovascular coil embolization was successful for the present ruptured PCA aneurysm with VBD.
\end{abstract}

Key words: coil embolization, posterior cerebral artery aneurysm, vertebrobasilar dolichoectasia, endovascular treatment, subarachnoid hemorrhage

\section{Introduction}

Vertebrobasilar dolichoectasia (VBD) is an altered configuration of the vertebrobasilar artery characterized by severe elongation and ectasia. VBD sometimes results in brain ischemia, ${ }^{20,22)}$ hemorrhage, ${ }^{20,24,25)}$ cranial nerve palsy, ${ }^{22,24)}$ symptoms due to compression of brain stem, ${ }^{10,22)}$ and hydrocephalus. ${ }^{22,28)}$ VBD will hinder endovascular treatment of an associated distal lesion because of the elongation and tortuosity of the access route. Here, we report successful coil embolization of a ruptured posterior cerebral artery (PCA) aneurysm associated with VBD.

\section{Case Report}

A 74-year-old man, who was previously treated for diabetes mellitus and myocardial infarction and had been taking aspirin for medication, suddenly lost consciousness at home and was transferred to our hospital. He recovered consciousness in the ambulance during transfer but lost consciousness again before he reached the hospital. On arrival, he was comatose.

Computed tomography (CT) was immediately performed and revealed severe subarachnoid hemorrhage (Fig. 1). Three-dimensional CT angiography and reconstructed CT showed a PCA aneurysm located in the right

Received October 19, 2010; Accepted February 16, 2011
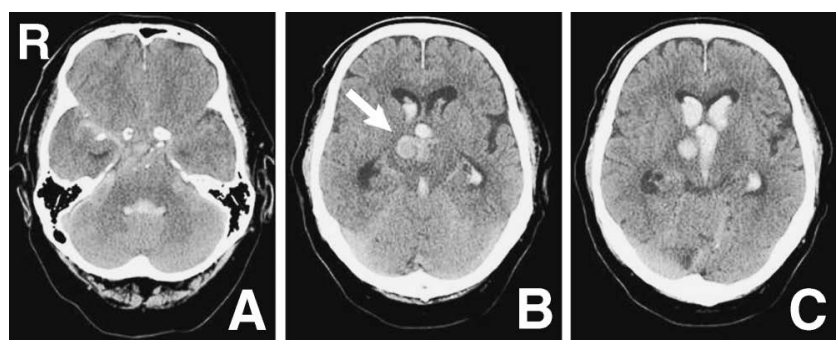

Fig. 1 Computed tomography scans on admission showing subarachnoid hemorrhage in the basal cistern (A), and intracerebral (arrow) and ventricular hemorrhages (B, C).

hypothalamus and VBD (Fig. 2). The patient recovered consciousness gradually but showed mild left hemiparesis. Angiography showed a ruptured aneurysm at the $\mathrm{P}_{1}$ portion according to the Zeal and Rhoton segmentation scheme for the $\mathrm{PCA}^{32)}$ (Fig. 3). The vertebrobasilar artery was severely elongated and ectatic. The VBD contained no thrombus. The right posterior communicating artery was hypoplastic.

Considering that the aneurysm rupture had recurred, the aneurysm was buried in the right hypothalamus, and the patient had taken aspirin for old myocardial infarction, difficulties were anticipated with the surgical procedure. We decided to treat this patient using an endovascular approach. A 6-Fr sheath was inserted into the right 

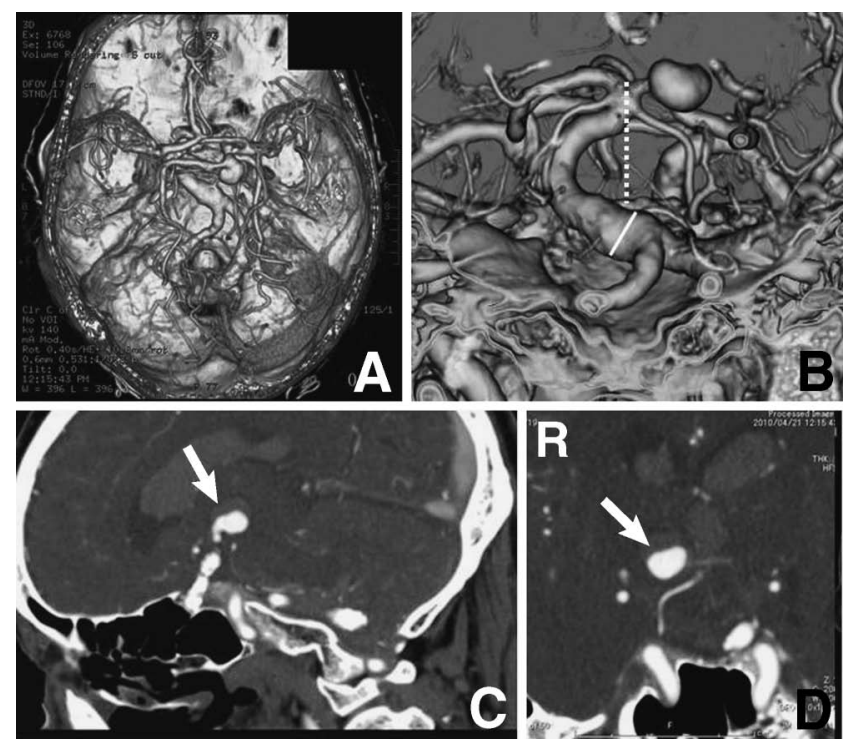

Fig. 2 A, B: Three-dimensional computed tomography angiograms, head-to-foot view (A) and posteroanterior view (B), showing severe elongation of the bilateral vertebral arteries and basilar artery, and ectasia at the proximal basilar artery. The distance from the dorsum sellae to the basilar tip (white dotted line) is $22.9 \mathbf{~ m m}$. The ectasia of the basilar artery (white line) is $10.3 \mathrm{~mm}$. C, D: Reconstructed computed tomography scans with contrast medium, sagittal view (C) and coronal view (D), showing subarachnoid, intracerebral, and intraventricular hemorrhages, and the aneurysm in the hypothalamus (arrow).
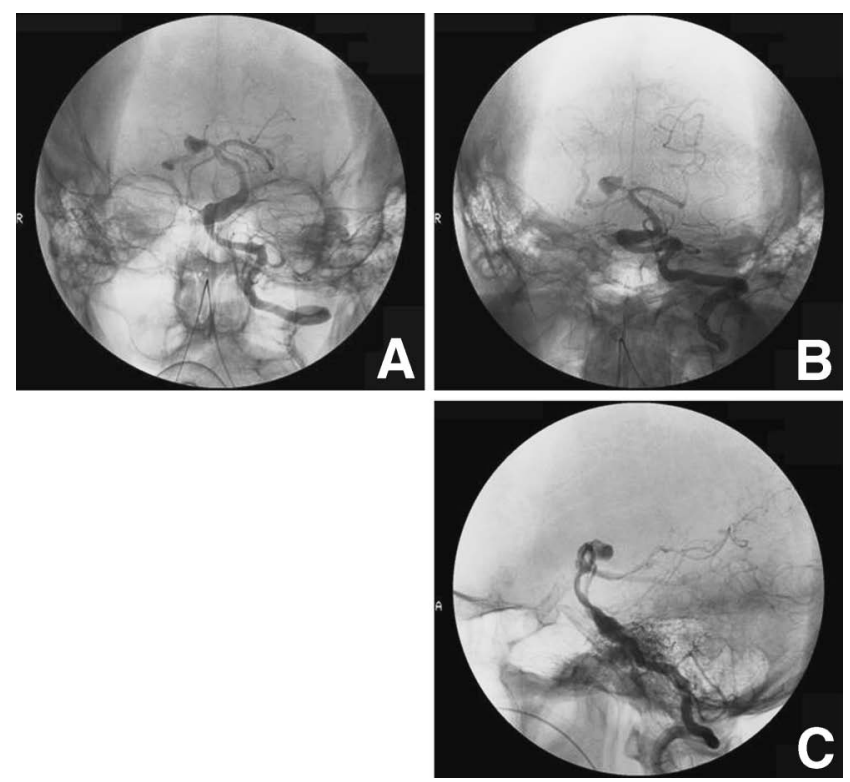

Fig. 3 Left vertebral angiograms, anteroposterior view (A), Towne's view (B), and lateral view (C), showing a severely elongated and dilated vertebrobasilar artery and right $P_{1}$ aneurysm.

femoral artery. A 6-Fr guiding catheter was then advanced as deeply as possible into the vertebral artery to stabilize the microcatheter. The microcatheter was shaped by
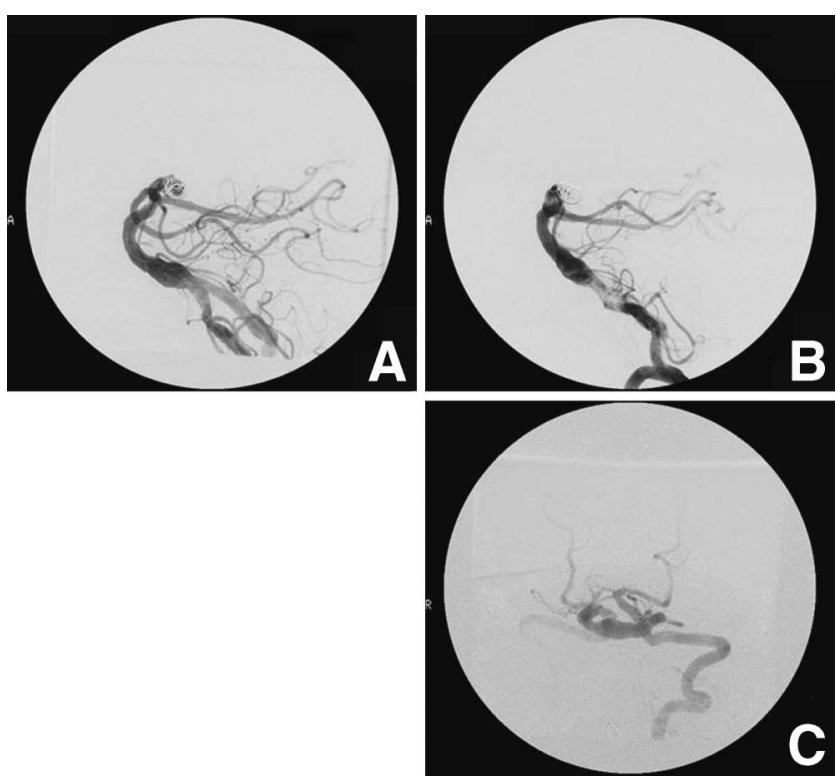

Fig. 4 Left vertebral angiograms, lateral view, after the first coil was inserted (A) and after treatment (B) showing the aneurysm is well embolized, and Towne's view after treatment (C) showing that the aneurysm is well embolized and that posterior cerebral artery flow is maintained. The view is obscured at this angle because of the patient's shoulder.
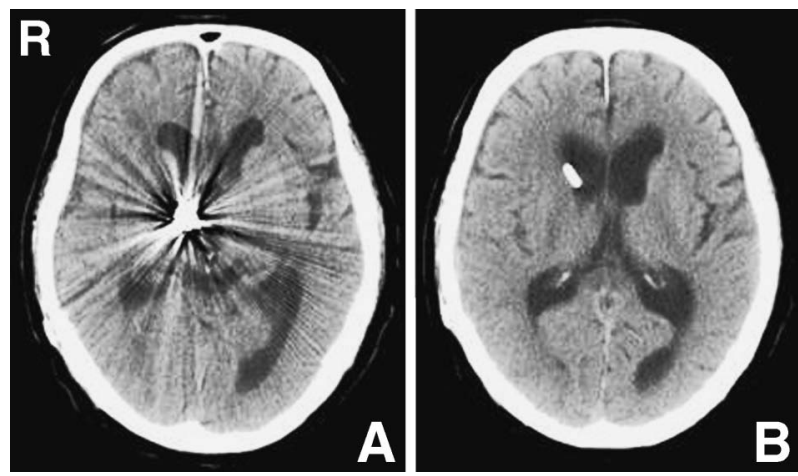

Fig. 5 Computed tomography scans before discharge revealing coil artifact in the right hypothalamus (A), but no infarcts in the right thalamus and posterior cerebral artery (B).

steaming to match the bend of the aneurysm, the $\mathrm{P}_{1}$ segment, and the basilar artery. The microcatheter was carefully advanced via the VBD and inserted into the aneurysm. Guglielmi detachable coils (total length $59 \mathrm{~cm}$ ) were inserted into the aneurysm (Fig. 4A). The aneurysm was well embolized, and flow in the parent artery was maintained (Fig. 4B, C).

No complications were seen perioperatively. After the procedure, the patient recovered consciousness. There was no evidence of delayed neurological worsening during the vessel spasm period. Although ventriculoperitoneal shunting was required for hydrocephalus, the patient gradually recovered (Fig. 5). Eventually, he was 
able to walk with assistance and was transferred to another hospital for rehabilitation.

\section{Discussion}

VBD is characterized by severe elongation, ectasia, and tortuosity. The normal basilar tip is located within the 20 mm quadrant from the dorsum sellae. ${ }^{12)}$ The distance from the dorsum sellae to the basilar tip varies between 1 and 15 $\mathrm{mm}$, and the distance is over $10 \mathrm{~mm}$ in $10 \%$ of cases. ${ }^{17)}$ The working definition for elongation of VBD is over $21 \mathrm{~mm}$ from the dorsum sellae to the basilar tip. The ordinary diameter of the basilar artery ranges from $1.5 \mathrm{~mm}$ to 3.5 $\mathrm{mm},{ }^{31)}$ and angiographical measurements of the basilar artery averaged $4 \mathrm{~mm} .{ }^{1)}$ Ectasia of greater size is also known, as the average diameter in 15 cases of dolichoectasia of the basilar artery was $8.6 \mathrm{~mm} .{ }^{22}$ In our case, the distance from the dorsum sellae to the basilar tip was $22.9 \mathrm{~mm}$, and the maximum diameter of ectasia of the basilar artery was $10.3 \mathrm{~mm}$.

Histological study of VBD at autopsy ${ }^{22)}$ has revealed disruption of the elastic lamina, atheroma of the intima, fibrous changes, calcification, and organization of the media in vessel walls, increased number of capillaries, and disruption of the elastic fiber of the adventitia. Thrombus is sometimes seen in $\mathrm{VBD}^{30}$ ) and may cause thromboembolic complications during endovascular procedures. This patient had been taking aspirin for myocardial infarction, which may have reduced the risk of a thromboembolic complication.

Elongation and ectasia are generally thought to be due to atherosclerosis in usual cases of VBD. ${ }^{22,23)}$ However, congenital factors ${ }^{4,12,24,27)}$ or arterial dissection ${ }^{19,21)}$ are suspected to affect the formation of some cases of VBD. The proximal portion is readily changed in atherosclerotic type VBD, whereas total and peripheral changes frequently occur in congenital type VBD. ${ }^{2,4,7,31)}$ Congenital dysplasia of the media is seen in VBD, and hypertension and/or other factors may be secondary causes. Subarachnoid hemorrhage is not a common issue in VBD of the atherosclerotic type, whereas the incidence of subarachnoid hemorrhage increases in congenital or dissecting type VBD. ${ }^{2,6,9,10,21)}$ We considered the present case of VBD to be the atherosclerotic type, and this may have been a factor in the absence of severe problems despite using the VBD as the access route. When considering endovascular treatment via a congenital or dissecting type VBD, the surgeon should be aware that the more fragile VBD will increase the possibility of complications. If the posterior communicating artery (PCoA) is large enough to pass the microcatheter and if the tortuosity of the internal carotid artery is not severe, endovascular treatment via the internal carotid artery and the PCoA may be feasible and would avoid the risk of using the VBD as an access route.

The incidence of PCA aneurysm is $0.6-1.2 \% .{ }^{11,26,29)}$ Aneurysms may occur at the proximal $\mathrm{PCA}^{3,14,29)}$ at earlier ages, ${ }^{8)}$ and tend to be associated with other aneurysms. ${ }^{29)}$ PCA aneurysms frequently become large, ${ }^{5,8}$ so other manifestations, except for subarachnoid hemorrhage, are common. Manifestations caused by brain stem com- pression, such as somnolence, amnesia, hemianopia, and cranial nerve palsy, have been reported.3,29) The pterional $^{11,14)}$ and subtemporal ${ }^{11,14)}$ approaches are ordinarily used for $\mathrm{P}_{1}-\mathrm{P}_{2}$ aneurysms. A transchoroidal fissure approach is typically considered for high-positioned $\mathrm{P}_{2}$ aneurysms. ${ }^{15)}$ The occipital interhemispheric fissure is normally used to approach more peripheral aneurysms that occur at $\mathrm{P}_{3}$ or $\mathrm{P}_{4} \cdot{ }^{14)}$ These approaches were not thought to easily reach the present aneurysm. Treatment of PCA aneurysms with VBD is not well known. Three cases of basilar tip aneurysm with megadolichobasilar anomaly were treated using a trans-third-ventricular approach. ${ }^{16)}$ The location of the aneurysm in the $\mathrm{P}_{1}$ segment to the right of the midline and buried in the right hypothalamus would have made the use of this approach more difficult.

Two endovascular treatment methods for PCA aneurysms have been documented. Coil embolization of aneurysms has been reported for selective use in berry or saccular type aneurysms, ${ }^{3,29)}$ and parent artery occlusion (PAO) has been used for giant or serpentine aneurysms. ${ }^{2,3,13,29)}$ Both of these treatment types are effective for PCA aneurysms. The reason that PAO has shown a good outcome in this environment is the presence of a rich collateral network. Collateral flow includes that of the long circumflex arteries (branches of the $\mathrm{P}_{1}$ segment) and the superior cerebellar artery, the lateral or medial posterior choroidal artery and the anterior choroidal artery, the splenial artery from $\mathrm{P}_{3}$ or $\mathrm{P}_{4}$ and the pericallosal artery, and the temporal branches of the PCA and middle cerebral artery. PAO has been used for treatment of basilar artery and PCA symptomatic dolichoectasia. ${ }^{2)}$ However, vessels proximal to the PCA have a high incidence of perforators (e.g., thalamogeniculate groups), and PAO risks disturbance of these perforators. PAO for the endovascular treatment of PCA aneurysms requires accurate anatomical knowledge and careful consideration of the indications. The complications of PAO for a PCA aneurysm are hemianopia, cranial nerve palsy, and brain stem symptoms from perforator disturbance, although comprehensive prediction of the complications of PAO is difficult. PCA aneurysms should be embolized selectively, if possible.

We treated the present case using a simple technique. The tortuosity of the access route often makes microcatheter and microguidewire control difficult. In such cases, a coaxial guiding system ${ }^{18)}$ should be used to stabilize the microcatheter. However, a complex system carries the risk of complications. If the treatment can be done safely, a simple system should be used. The aneurysm in this case was saccular, but did not arise from an obvious vessel bifurcation. Postoperative changes to the parent artery or the coil compaction were also possible. Careful follow up is especially important, even more so than in ordinary cases of coil embolization for saccular aneurysms.

The present case of a rare PCA aneurysm associated with VBD had shifted to a cranial location due to the elongated vertebrobasilar artery and was buried in the right hypothalamus. Complications were expected for endo- 
vascular treatment of the PCA aneurysm via the VBD, but our treatment method using coil embolization induced no complications related to the procedure, and the patient showed good recovery. Despite the severe elongation and tortuosity of the access route, our results indicate that cases of PCA aneurysm with VBD can be successfully treated by endovascular surgery in some situations.

\section{References}

1) Busch W: [Contribution to the morphology and pathology of the basilar artery. Results of the study of 1000 brains]. Arch Psychiatr Nervenkr 208: 326-344, 1966 (German)

2) Chao KH, Riina HA, Heier L, Steig PE, Gobin YP: Endovascular management of dolichoectasia of the posterior cerebral artery report. AJNR Am J Neuroradiol 25: 1790-1791, 2004

3) Ciceri EF, Klucznik RP, Grossman RG, Rose JE, Mawad ME: Aneurysms of the posterior cerebral artery: classification and endovascular treatment. AJNR Am J Neuroradiol 22: 27-34, 2001

4) Doran SE, Deveikis JP, Chandler WF: Dolichoectasia of the anterior cerebral arteries in an adolescent. AJNR Am J Neuroradiol 16: 1548-1550, 1995

5) Drake CG: Giant intracranial aneurysms: experience with surgical treatment in 174 patients. Clin Neurosurg 26: 12-95, 1979

6) Drake CG, Peerless SJ: Giant fusiform intracranial aneurysms: review of 120 patients treated surgically from 1965 to 1992. J Neurosurg 87: 141-162, 1997

7) Dziewasa R, Freund M, Lüdemann P, Müller M, Ritter M, Droste DW, Stögbauer F: Treatment options in vertebrobasilar dolichoectasia-case report and review of the literature. Eur Neurol 49: 245-247, 2003

8) Ferrante L, Acqui M, Trillò G, Lunardi P, Fortuna A: Aneurysms of the posterior cerebral artery: do they present specific characteristics? Acta Neurochir (Wien) 138: 840-852, 1996

9) Ferry PC, Kerber C, Peterson D, Gallo AA Jr: Arteriectasis, subarachnoid hemorrhage in a three-month-old infant. Neurology 24: 494-500, 1974

10) Findlay JM, Hao C, Emery D: Non-atherosclerotic fusiform cerebral aneurysms. Can J Neurol Sci 29: 41-48, 2002

11) Gi H, Uno J, Ikai Y, Inoha S, Koga H, Yamaguchi S, Nagaoka S: [Seven cases of posterior cerebral artery aneurysms]. No Shinkei Geka 35: 345-352, 2007 (Japanese)

12) Greitz T, Lofstedt S: The relationship between the third ventricle and the basilar artery. Acta Radiol 42: 85-100, 1954

13) Hallacq P, Piotin M, Moret J: Endovascular occlusion of the posterior cerebral artery for the treatment of $\mathrm{p} 2$ segment aneurysms: retrospective review of a 10-year series. AJNR Am J Neuroradiol 23: 1128-1136, 2002

14) Honda M, Tsutsumi K, Yokoyama H, Yonekura M, Nagata I: Aneurysms of the posterior cerebral artery: retrospective review of surgical treatment. Neurol Med Chir (Tokyo) 44: 164-168, 2004

15) Hosoi K, Tomita H, Tamaki N: [Clipping of an aneurysm of the posterior cerebral artery via the transcortical transchoroidal-fissure approach: a case report]. No Shinkei Geka
28: 89-93, 2000 (Japanese)

16) Kodama N, Sasaki T, Sakurai Y: Transthird ventricular approach for a high basilar bifurcation aneurysm. Report of three cases. J Neurosurg 82: 664-668, 1995

17) Krayenbühl H, Yaşargil MG, Huber P: Cerebral Angiography, ed 2. Stuttgart, New York, Georg Thieme Verlag, 1982, pp 152-155

18) Lee TH, Choi CH, Park KP, Sung SM, Lee SW, Lee BH, Kim DH, Kim HJ, Kim CW, Kim S: Techniques for intracranial stent navigation in patients with tortuous vessels. AJNR Am J Neuroradiol 26: 1375-1380, 2005

19) Mizutani T, Miki Y, Kojima H, Suzuki H: Proposed classification of nonatherosclerotic cerebral fusiform and dissecting aneurysms. Neurosurgery 45: 253-260, 1999

20) Nakamura Y, Hirayama T, Ikeda K: Clinicoradiologic features of vertebrobasilar dolichoectasia in stroke patients. $J$ Stroke Cerebrovasc Dis Epub 2010 Sep 11

21) Nakatomi H, Segawa H, Kurata A, Shiokawa $Y$, Nagata $K$, Kamiyama H, Ueki K, Kirino T: Clinicopathological study of intracranial fusiform and dolichoectatic aneurysms: insight on the mechanism of growth. Stroke 31: 896-900, 2000

22) Okada Y, Shima T, Nishida M, Yamane K, Okita S, Hatayama T, Naoe Y, Nishida T: [Clinicopathoradiological studies in 15 cases of megadolichobasilar anomaly]. No To Shinkei 46: 257-262, 1994 (Japanese)

23) Oki S, Shima T, Ishikawa $S$, Uozumi T, Yamane T, Hara $H$ : [A case of intracranial arterial dolicho-ectasia] (author's transl). No To Shinkei 31: 593-600, 1979 (Japanese)

24) Owada K, Suzuki J, Iwabuchi T: [Megadolichobasilar anomaly] (author's transl). No Shinkei Geka 2: 699-704, 1974 (Japanese)

25) Passero SG, Calchetti B, Bartalini S: Intracranial bleeding in patients with vertebrobasilar dolichoectasia. Stroke 36: 1421-1425, 2005

26) Pia HW, Fontana H: Aneurysms of the posterior cerebral artery. Locations and clinical pictures. Acta Neurochir (Wien) 38: 13-35, 1977

27) Sacks JG, Lindenburg R: Dolicho-ectatic intracranial arteries: symptomatology and pathogenesis of arterial elongation and distention. Johns Hopkins Med J 125: 95-106, 1969

28) Siddiqui A, Chew NS, Miszkiel K: Vertebrobasilar dolichoectasia: a rare cause of obstructive hydrocephalus: case report. Br J Radiol 81: 123-126, 2008

29) van Rooij WJ, Sluzewski M, Beute GN: Endovascular treatment of posterior cerebral artery aneurysms. AJNR Am J Neuroradiol 27: 300-305, 2006

30) Vieco PT, Maurin EE 3rd, Gross CE: Vertebrobasilar dolichoectasia: evaluation with CT angiography. AJNR Am J Neuroradiol 18: 1385-1388, 1997

31) Yu YL, Moseley IF, Pullicino P, McDonald WI: The clinical picture of ectasia of the intracerebral arteries. J Neurol Neurosurg Psychiatry 45: 29-36, 1982

32) Zeal AA, Rhoton AL Jr: Microsurgical anatomy of the posterior cerebral artery. J Neurosurg 48: 534-559, 1978

Address reprint requests to: Shinya Yamaguchi, MD, Department of Neurosurgery, Hamanomachi Hospital, 3-5-27 Maiduru, Chuou-ku, Fukuoka 810-8539, Japan.

e-mail: s-yamaguchi23@samba.ocn.ne.jp 